\title{
Synthesis of Nitrogen Heterocycles via Directed Carbonylative C-C Bond Activation of Cyclopropanes
}

\author{
Andrew G. Dalling and John F. Bower*
}

\begin{abstract}
This review concentrates on recent developments from our laboratory concerning the Rh-catalyzed carbonylative $\mathrm{C}-\mathrm{C}$ bond activation of cyclopropanes. Specifically, we have found that $\mathrm{N}$-based directing groups are effective at controlling the regioselectivity of $\mathrm{C}-\mathrm{C}$ bond activation during the formation of rhodacyclopentanone intermediates. These engage tethered $\pi$-unsaturated components (e.g. alkenes) or conventional nucleophiles in cycloaddition and heterocyclization processes, respectively. Using this approach, direct and modular access to a wide range of complex heterocyclic ring systems is achieved. The review summarizes the scope of our methodologies and outlines key mechanistic features.
\end{abstract}

Keywords: C-C bond activation · Carbonylation $\cdot$ Cycloaddition $\cdot$ Cyclopropane $\cdot$ Rhodium

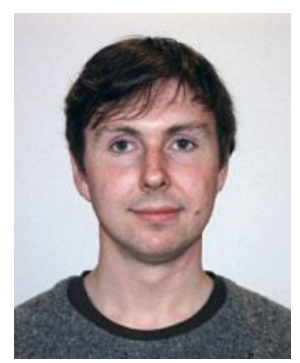

\section{John F. Bower}

obtained his MSci degree in 2003 from the University of Bristol, where he remained to study for his $\mathrm{PhD}$ degree (2007) under the guidance of Professor Timothy Gallagher. He then undertook postdoctoral appointments with Professor Michael Krische at the University of Texas at Austin (2007-2008) and Professor Timothy Donohoe at the University of Oxford (2008-2010). In 2010, he was awarded a Royal Society University Research Fellowship and commenced his independent career at the University of Bristol. Bower's research has been recognized by a number of awards, including the 2013 Royal Society of Chemistry HarrisonMeldola Memorial Prize and the 2015 Royal Society of Chemistry Hickinbottom Award.

\footnotetext{
${ }^{\star}$ Correspondence: Prof. J. F. Bower School of Chemistry, University of Bristol Bristol, BS8 1TS, United Kingdom
} E-mail: john.bower@bristol.ac.uk

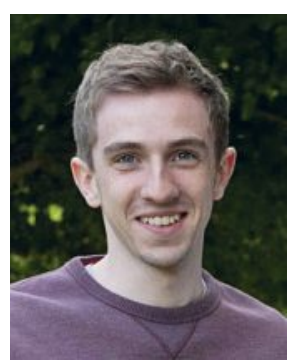

Andrew G. Dalling received his undergraduate MSci degree (First Class) from the University of Birmingham in 2016, receiving the Alfred Bader Prize upon graduation. He completed his final year research project in the laboratory of Professor John Fossey, where he worked on the kinetic resolution of chiral azides and alkynes. Following this, he moved to the University of Bristol to conduct his PhD studies under the guidance of Professor John Bower. His current research focuses on the development and application of rhodium-catalyzed $\mathrm{C}-\mathrm{C}$ bond activation triggered methodologies.

\section{Introduction}

There has been considerable recent interest in methodologies that provide flexible access to ' $\mathrm{sp}^{3}$-rich' building blocks and scaffolds. ${ }^{[1]}$ One broad approach to this challenge is to identify catalysis platforms that harness readily available and stereochemically defined initiating motifs. Within this context, methodologies that exploit metal insertion into small ring systems are particularly appealing. ${ }^{[2]}$ For cyclopropane-based $\mathrm{C}-\mathrm{C}$ bond activation methodologies, specialised substrates are usually required (e.g. vinyl cyclopropanes, ${ }^{[3]}$ alkylidenecyclopropanes, ${ }^{[4]}$ cyclopropenes ${ }^{[5]}$ ), and processes that exploit less activated cyclopropanes have been slow to emerge.[6] This situation is especially surprising given that stoichiometric metal insertion into non-activated cyclopropanes has been known for over 60 years. ${ }^{[7]}$ Two key challenges associated with cyclopropane-based processes are (a) controlling the regiochemistry of $\mathrm{C}-\mathrm{C}$ oxidative addition and (b) harnessing the resulting metallacyclobutane prior to deleterious $\beta$-hydride elimination. ${ }^{[8]}$ We have addressed these issues by developing directing group-controlled processes where fast carbonylation of a rhodacyclobutane intermediate provides a relatively stable rhodacyclopentanone. The key synthetic advantage of this approach is that the substrates (i.e. 1) are easily accessed from readily available and stereodefined cyclopropyl carboxylates $\mathbf{2}$ (Scheme 1A). ${ }^{[9]}$ Trapping of the key rhodacyclopentanone intermediate 3 then allows access to a diverse array of heterocyclic scaffolds, many of which are prevalent in natural products and pharmaceutical agents (Scheme 1B). ${ }^{10]}$ This review focuses on methodologies developed within our group that are based on this approach.

\section{Directed Carbonylative $(3+1+2)$ Cycloadditions of Aminocyclopropanes}

Our studies on carbonylative $\mathrm{C}-\mathrm{C}$ bond activation of aminocyclopropanes commenced in 2013 with the discovery that regioselective metallacycle formation can be promoted using suitable $\mathrm{N}$-directing groups. ${ }^{[11]}$ In early experiments, we found that exposure of carbamate-protected aminocyclopropane $\mathbf{4}$ to a cationic $\mathrm{Rh}(\mathrm{I}$ ) source delivered exclusively linear alkene $\mathbf{5}$, presumably via directed formation of rhodacyclobutane 6 (Scheme 2A). In the absence of a directing group, the same 
catalyst system inserts into the most sterically accessible cyclopropane $\mathrm{C}-\mathrm{C}$ bond; accordingly, a nitrogen-based directing group is crucial for enforcing contrasteric $\mathrm{C}-\mathrm{C}$ bond activation. Treatment of carbamate-protected aminocyclopropanes 7 with stoichiometric $\left[\mathrm{Rh}(\mathrm{CO})_{2} \mathrm{Cl}\right]_{2}$, allowed confirmation of the role of the directing group through $\mathrm{X}$-ray crystallographic analysis of rhodacyclopentanones 8. ${ }^{[12,13]}$

With a suitable $\mathrm{C}-\mathrm{C}$ bond activation mode established, we sought to incorporate it into a prototype multicomponent carbonylative $(3+1+2)$ cycloaddition process involving $\mathrm{N}$-tethered alkynes (Scheme 2C). Here, the choice of $\mathrm{N}$-directing group is critical as it must be sufficiently Lewis basic to outcompete the alkyne for coordination of the Rh-catalyst ( $\mathbf{9}$ to $\mathbf{1 0}$ ), but also labile enough to dissociate at the stage of $\mathbf{1 0}$ and allow alkyne coordination (to 11). For the process in Scheme 2C, an evaluation of various $\mathrm{N}$-directing groups combined with the synthesis of a series of rhodacyclopentanone complexes $(\mathbf{8 a}-\mathbf{c})$ revealed that strongly Lewis basic ureas offer substantially enhanced efficiencies compare to carbamates and amides (Scheme 2B). ${ }^{[13]}$ Optimized reaction conditions employ a neutral Rh-source modified with $\mathrm{P}(3,5$ $\left.\left(\mathrm{CF}_{3}\right)_{2} \mathrm{C}_{6} \mathrm{H}_{3}\right)_{3}$, an atmospheric pressure of $\mathrm{CO}$ and $\mathrm{PhCN}$ as solvent; the latter allows higher TONs compared to less coordinating solvents (Scheme 2C). The process tolerates a range of alkynes, including alkyl (9a) and aryl (9b) substituted variants, while also allowing access to more stereochemically complex scaffolds (e.g. 12c,d), albeit with modest levels of diastereocontrol.

The process outlined in Scheme 2C requires a strongly Lewis basic directing group to outcompete the alkyne moiety for coordination of the Rh-catalyst prior to $\mathrm{C}-\mathrm{C}$ oxidative addition. Cognizant of this, subsequent studies investigated the feasibility of related cycloadditions involving aminocyclopropanes, $\mathrm{CO}$ and more weakly coordinating alkenes (Scheme 3).[14] Here, we found that less Lewis basic and more synthetically flexible carbamates could be used as the directing group, with, for example, Cbz-protected system 13a cyclizing in $80 \%$ yield and with high selectivity for the trans-ring junction to give 14a. The reaction conditions outlined in Scheme 3A were optimized with the specific aim of enhancing diastereoselectivity for systems with substituents at $\mathrm{R}^{1}$ or $\mathrm{R}^{2}$ to afford stereochemically complex cycloadducts including 14b-d. Extensive investigations revealed a number of critical factors, the most important of which was the use of a cationic Rh(I)-system. Here, the additional vacant coordination site ( $v s$. neutral Rh(I)-systems) likely facilitates retrocarbonylation from the rhodacyclopentanone intermediate, which, in turn,

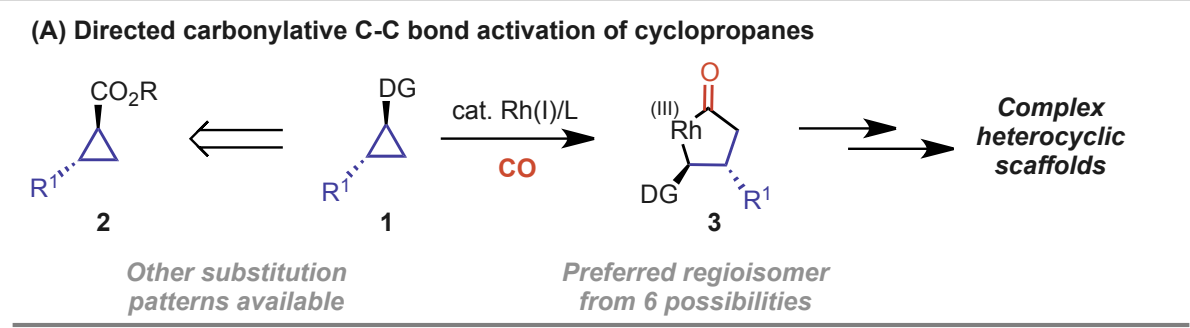

(B) Compounds containing core motifs that can be accessed through our catalysis platform

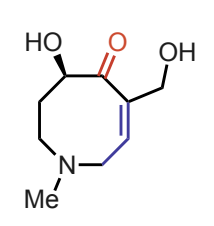

Otonecine

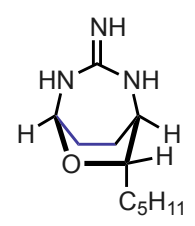

(+)-monanchorin

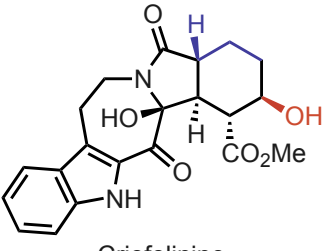

Criofolinine

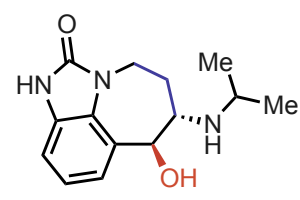

$( \pm)$

Scheme 1. Directed carbonylative $\mathrm{C}-\mathrm{C}$ bond activation.

(A) Preliminary insertion experiments

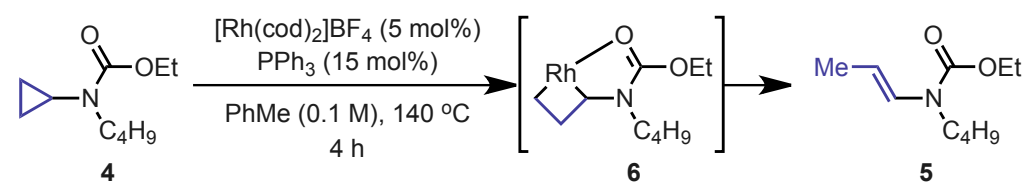

(B) Relative donor strengths of potential directing groups

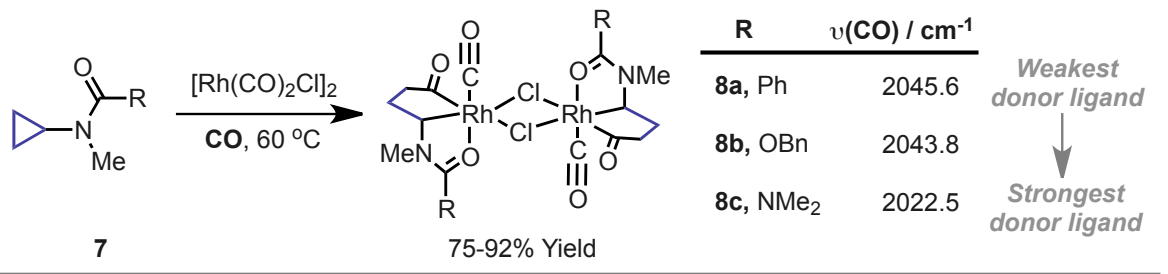

(C) $A(3+1+2)$ cycloaddition
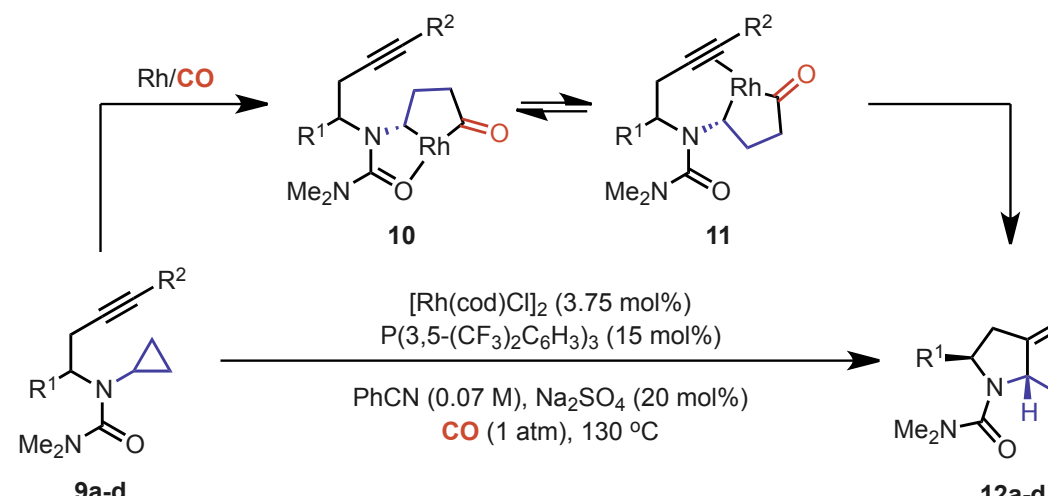

$[\mathrm{Rh}(\operatorname{cod}) \mathrm{Cl}]_{2}(3.75 \mathrm{~mol} \%)$
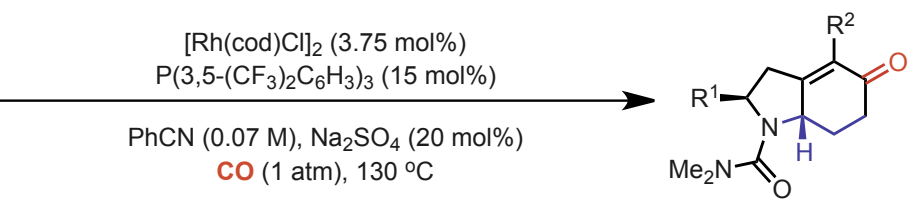

$\mathrm{CO}(1 \mathrm{~atm}), 130^{\circ} \mathrm{C}$

$12 a-d$

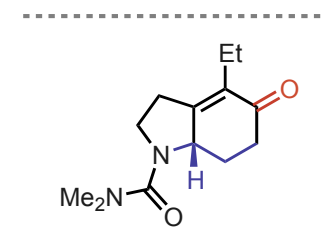

12a, 64\% Yield

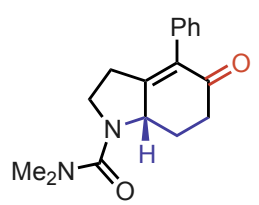

12b, 66\% Yield

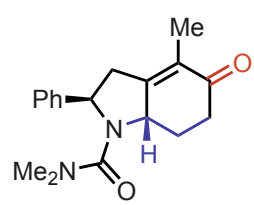

12c, $61 \%$ Yield (5:2 d.r.)

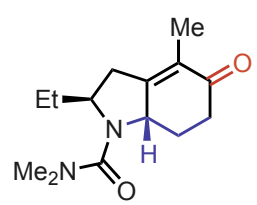

12d, 58\% Yield (4:1 d.r.)

Scheme 2. Preliminary mechanistic studies leading to $(3+1+2)$ cycloadditions of aminocyclopropanes, $\mathrm{CO}$ and tethered alkynes.

renders rhodacyclopentanone formation reversible (Scheme 3B). ${ }^{[15]}$ In this scenario, diastereoselectivity with respect to $\mathrm{R}^{1}$ and $\mathrm{R}^{2}$ is controlled by the relative facility of alkene insertion into the two diastereomeric rhodacyclic $\pi$-complexes (15a and $\mathbf{1 5 b}$ ). Under the same conditions, neutral Rh(I)precatalysts provided low levels of dias- 
tereocontrol, likely because rhodacyclopentanone formation is less reversible and carbonylative $\mathrm{C}-\mathrm{C}$ bond activation has minimal selectivity for $\mathbf{1 5 a} v s$. 15b. For the 'cationic conditions' in Scheme 3A, isobutyramide and dimethyl fumarate ${ }^{[16]}$ additives were found to be beneficial to reaction rate and yield, with their role possibly being the stabilization of off-cycle species.

The chemistry so far exploits non-substituted aminocyclopropane units; however, we have found that more highly substituted systems are also effective. To gain insight into the regiochemical preference of $\mathrm{C}-\mathrm{C}$ bond activation for cis- and trans-1,2-disubstituted cyclopropanes a series of model rhodacyclopentanone intermediates were prepared (Scheme 4A). ${ }^{[14,17]}$ Exposure of trans-1,2-disubstituted substrate 16 to stoichiometric $\left[\mathrm{Rh}(\mathrm{CO})_{2} \mathrm{Cl}\right]_{2}$ provided a dimeric species $\mathbf{1 7}$ resulting from $\mathrm{Rh}$ insertion into the less hindered proximal $\mathrm{C}-\mathrm{C}$ bond a. Conversely, under analogous conditions, cis-1,2-disubstituted substrate $\mathbf{1 8}$ underwent preferential $\mathrm{C}-\mathrm{C}$ bond activation at more hindered proximal $\mathrm{C}-\mathrm{C}$ bond $\mathbf{b}$ to give 19. Thus, for cis-1,2-disubstituted cyclopropanes, where steric constraints are to some extent alleviated, activation of the more electron rich proximal $\mathrm{C}-\mathrm{C}$ bond is preferred.[18] The observations made in these stoichiometric studies translate to the regioselectivities observed in $(3+1+2)$ cycloaddition processes (Scheme 4B). ${ }^{[14]}$ For example, subjection of trans-20 to the conditions outlined in Scheme 3A provided 21 in $67 \%$ yield and with total regiocontrol, resulting from preferential activation of bond $\mathbf{a}$. Conversely, $(3+1+2)$ cycloaddition of cis20 occurred via bond $\mathbf{b}$ to provide cycloadduct 22. Thus, the relative stereochemistry of the cyclopropane unit controls the regioselectivity of $\mathrm{C}-\mathrm{C}$ bond activation and determines the stereochemistry of the cycloadduct. However, as will be seen later, the inherent regiochemical preference of rhodacyclopentanone formation does not always transfer to the regiochemistry of the product.

The processes discussed so far provide new six-membered rings by $(3+1+2)$ cycloadditions and can be thought of as homologues of the Pauson-Khand reaction. ${ }^{[19]}$ By reengineering the substrate, we have found that other classes of process can be achieved. For example, $\mathrm{N}$-cyclopropylacrylamides undergo mechanistically distinct $(7+1)$ cycloadditions to provide a modular entry to azocanes (Scheme 5). ${ }^{[17]}$ Here, the requirement of a relatively high reaction temperature $\left(150{ }^{\circ} \mathrm{C}\right)$ is presumably reflective of the strain associated with the newly formed azocane product. The methodology tolerates 1,1-disubstituted alkenes (e.g. 23), with
(A) Substrate scope using a cationic $\mathrm{Rh}(\mathrm{I})$-source
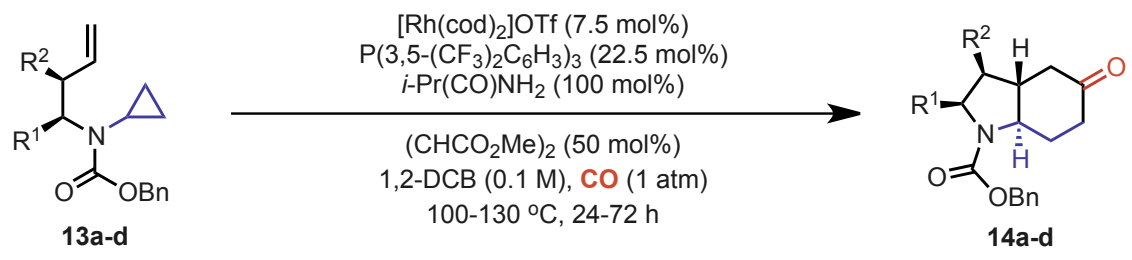

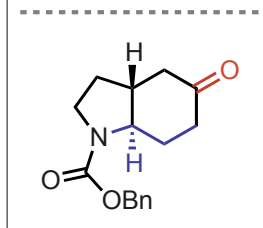

$14 a, 80 \%$ Yield $(>15: 1$ d.r. $)$<smiles>O=C1C[C@@H]2CCC(=O)[C@H](c3ccccc3)C[C@@H]2C1</smiles>

14b, $79 \%$ Yield (8:1:1 d.r.)

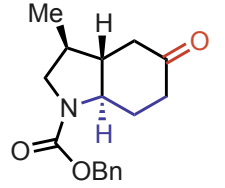

14c, $71 \%$ Yield (>15:1 d.r.)

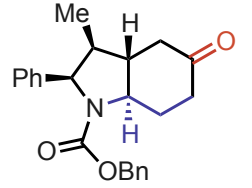

14d, 39\% Yield $(>15: 1$ d.r.)
(B) Diastereoselectivity via reversible rhodacyclopentanone formation

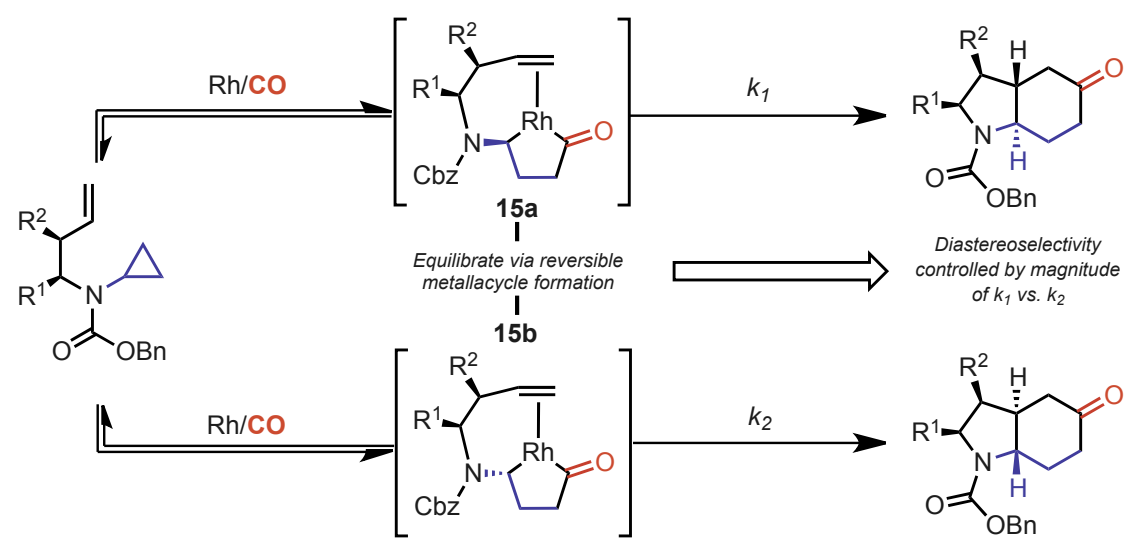

Scheme 3. Diastereoselective $(3+1+2)$ cycloadditions of cyclopropanes, CO and tethered alkenes.

(A) Synthesis of model rhodacyclopentanone complexes

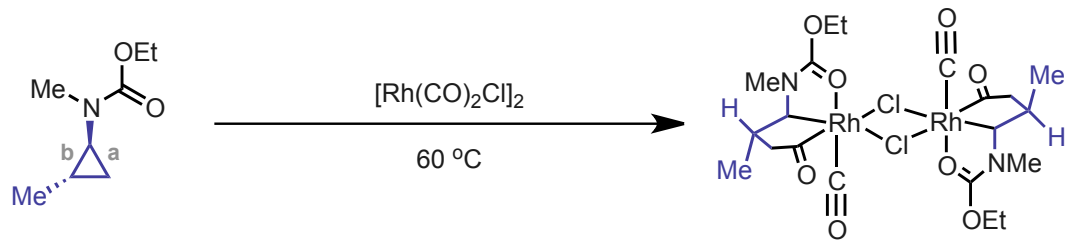

trans-16

activation of less hindered bond a

$17,58 \%$ Yield (X-ray)
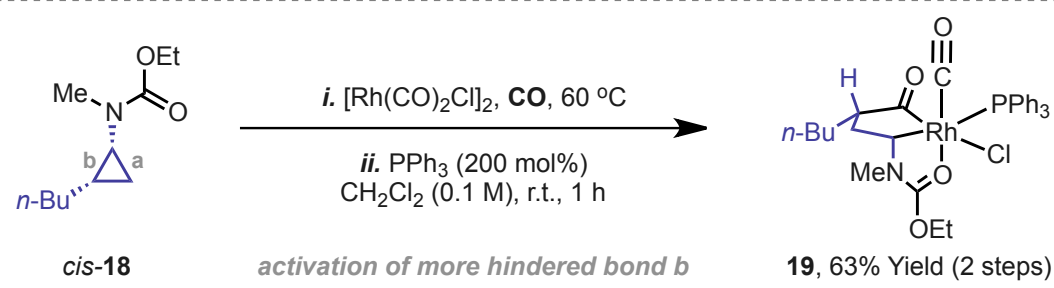

(B) Scope of substrates bearing 1,2-disubstituted cyclopropanes

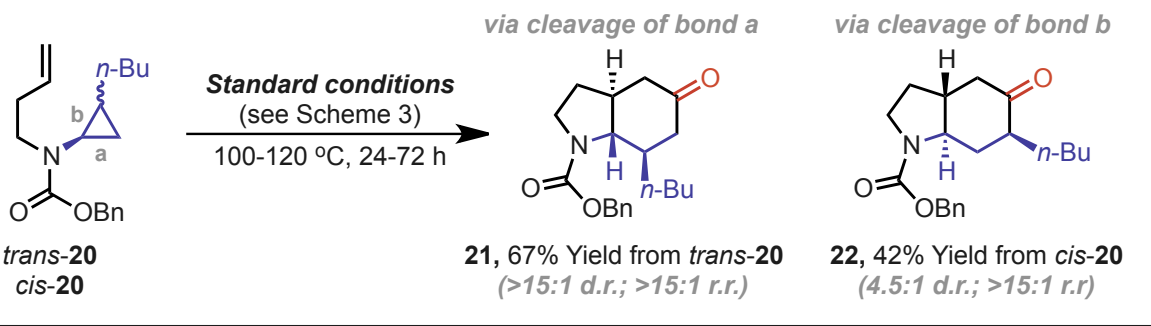

Scheme 4. Regioselective C-C bond activation of 1,2-disubstituted cyclopropanes. 
the efficiency of cyclization (to 24) largely independent of the steric and electronic demands of the $\mathrm{R}^{2}$ group. 1,2-Disubstituted aminocyclopropanes provided unexpected results, with both cis-25 and trans-25 affording the same azocane adduct (Scheme 5A). The outcome for cyclization of cis-25 was expected, but, for trans-25, formation of 26 requires cleavage of the less favored proximal cyclopropane $\mathrm{C}-\mathrm{C}$ bond $\mathbf{b}$ ( $c f$. Scheme 4). The most appealing mechanistic rationalization for this outcome invokes both reversible rhodacyclopentanone formation and reversible alkene insertion (Scheme 5B). In this scenario, alkene insertion into favored rhodacyclopentanone 27 (arising via activation of less-hindered proximal $\mathrm{C}-\mathrm{C}$ bond a) affords metallacycle 28, from which syn- $\beta$-hydride elimination via $\mathrm{C} 7-\mathrm{H}$ (to form the expected product) is not possible. However, equilibration via disfavored rhodacyclopentanone $\mathbf{2 9}$ provides 30, where syn- $\beta$-hydride elimination via $\mathrm{C} 7-\mathrm{H}$ can occur to provide the observed regioisomer of the product. Isotopic labelling studies support the proposed mechanistic pathway.

\section{Capture-Collapse Heterocyclizations}

In the previous section, cycloaddition reactions were achieved by the insertion of $\pi$-unsaturates into rhodacyclopentanone intermediates. We have found that species of this type are also susceptible to attack by pendant nucleophiles, and we anticipate that this observation will allow access to a wide range of challenging ring systems. In a prototype methodology, we demonstrated that carbonyl directed $\mathrm{C}-\mathrm{C}$ bond activation of cyclopropyl ureas $\mathbf{3 1}$ can be followed by 'capture' of the metallacycle $\mathbf{3 2}$ by the $\mathrm{NH}$ unit to afford 33 (Scheme 6A). ${ }^{[20]} \mathrm{At}$ this stage, $\mathrm{C}-\mathrm{N}$ reductive elimination ("collapse') is followed by either $\beta$-hydride elimination (to 34) or protodemetalation (to 35), with the latter pathway facilitated by the addition of benzoic acid. Thus, kinetically challenging 1,3-diazepane ring systems are generated via the intermediacy of kinetically accessible bicycles $\mathbf{3 3}$. The method is effective for accessing a range of challenging diazepanes, and the substrates are prepared in short order by reaction of aminocyclopropanes with $\mathrm{N}$-aryl or $\mathrm{N}$-alkyl isocyanates. Processes involving substituted cyclopropanes produced unexpected regiochemical outcomes, which were rationalized by invoking $\mathrm{C}-\mathrm{N}$ reductive elimination as the first irreversible step of the process (Scheme 6B,C). For example, trans-1,2-disubstituted cyclopropane 36 afforded 1,3-diazepane 37 as the major product, where $\mathrm{C}-\mathrm{C}$ bond activation of 'disfavored' bond $\mathbf{b}$ has occurred ( $c f$. Scheme 4). Although $\mathrm{C}-\mathrm{C}$ bond
(A) Scope of the $(7+1)$ cycloaddition-fragmentation process

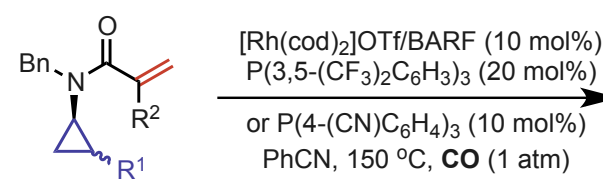

$23\left(R^{1}=H, R^{2}=P h\right)$ $25\left(R^{1}=M e, R^{2}=H\right)$

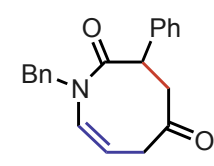

24, 63\% Yield

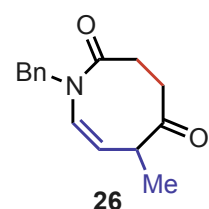

$63 \%$ Yield from trans-25 $50 \%$ Yield from cis-25
(B) Mechanistic rationale for the observed regiochemical outcome
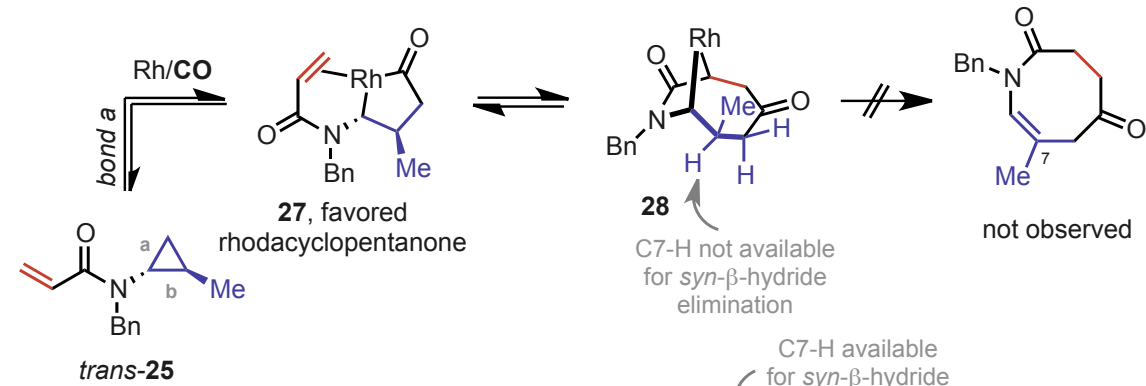

not observed

or syn- $\beta$-hydride

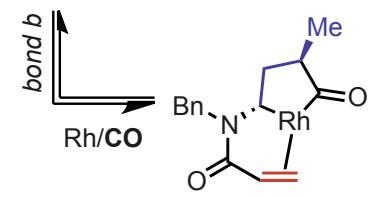

29, disfavored hodacyclopentanone
C7-H available

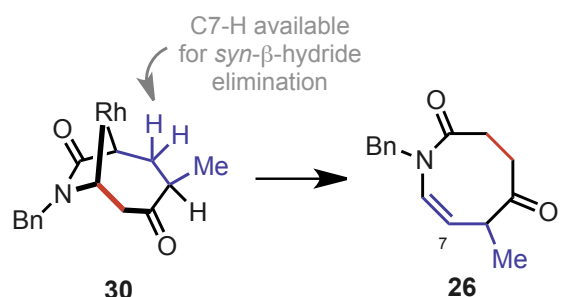

Scheme 5. Azocanes via a (7+1) cycloaddition-fragmentation strategy.

cleavage of bond $\mathbf{a}$ is preferred on steric grounds, $\mathrm{C}-\mathrm{N}$ reductive elimination from the resulting metallacycle $\mathbf{3 8}$ is likely to be slow due to the developing steric clash between the $\mathrm{Rh}$-center and the $\mathrm{R}^{3}$-substitutent. Accordingly, reversible metallacycle formation allows access to alternate metallacycle 39, which undergoes more facile $\mathrm{C}-\mathrm{N}$ reductive elimination (to $\mathbf{4 0}$ ) to provide the observed regioisomer of the product.

Capture-collapse heterocyclizations can also be extended to processes that involve $\mathrm{C}-\mathrm{C}$ bond forming reductive elimination from rhodacyclopentanones (Scheme 7A). [21] For $\mathrm{N}$-aryl systems 41a-c, directed rhodacyclopentanone formation (to $\mathbf{4 2}$ ) is followed by $\mathrm{C}-\mathrm{H}$ metalation (to 43 ), $\mathrm{C}-\mathrm{C}$ reductive elimination and protodemetalation to afford benzazepine ring systems. Thus, access to challenging heterocyclic systems is achieved by harnessing sequential $\mathrm{C}-\mathrm{C}$ bond activation and $\mathrm{C}-\mathrm{H}$ functionalization steps. Optimized conditions employ a cationic Rh(I)-system modified with electron-deficient phosphine ligands, in conjunction with a carboxylic acid additive, which likely facilitates the final protodemetalation step. A broad range of electron-rich and electron-poor arenes are tolerated, and the target benzazepine ring systems (e.g. $\mathbf{4 4 a - c )}$ are recognized as 'privileged' from a medicinal chemistry viewpoint. ${ }^{[22]}$ Replacement of the $\mathrm{N}$-aryl ring with an $\mathrm{N}$-vinyl unit provides direct access to a wider range of azepine ring systems, including unusual bicyclic variants (Scheme 7B). Mechanistic studies on $\mathrm{N}$-aryl based systems support $\mathrm{C}-\mathrm{C}$ reductive elimination as the first irreversible step in these processes.

\section{Other Classes of Cyclopropane Offer Further Flexibility}

The cycloadditions described above involve electron-rich aminocyclopropanes, which can be accessed by Curtius rearrangement of readily accessible and stereodefined cyclopropyl carboxylic acids (Scheme 8). Accordingly, from a broader strategic viewpoint, ' $\mathrm{sp}^{3}$-rich' metallacyclic intermediates are accessed by exploiting the strain embedded within small and stereodefined ring systems. To expand the utility of our approach, we sought to demonstrate the feasibility of processes that involve more demanding classes of readily available cyclopropane.

Within this context, $(3+1+2)$ cycloadditions of electron-neutral aminomethylcyclopropanes were explored. ${ }^{[23]}$ These processes are challenging because (a) they involve a less favorable six-ring chelate (vs. five-ring for aminocyclopropane methodologies, i.e. 45 vs. 46); (b) the cyclopropane is less nucleophilic, which leads to less efficient $\mathrm{C}-\mathrm{C}$ oxidative addition, and (c) exocyclic $\beta$-hydride elimination from $\mathbf{4 5}$ can compete with insertion of the $\pi$-unsaturate (Scheme 8). 
(A) 1,3-Diazepanes by $\mathrm{C}-\mathrm{N}$ reductive elimination

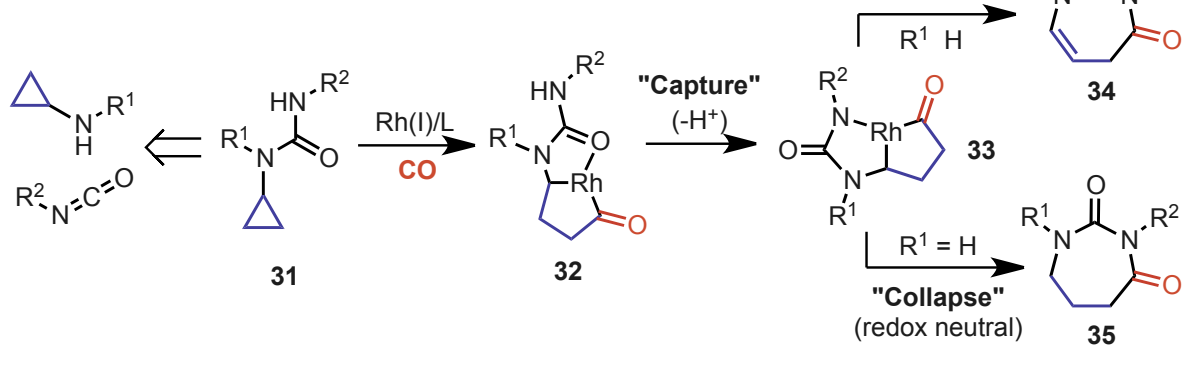

(B) Carbonylative heterocyclisations of trans-1,2-disubstituted systems

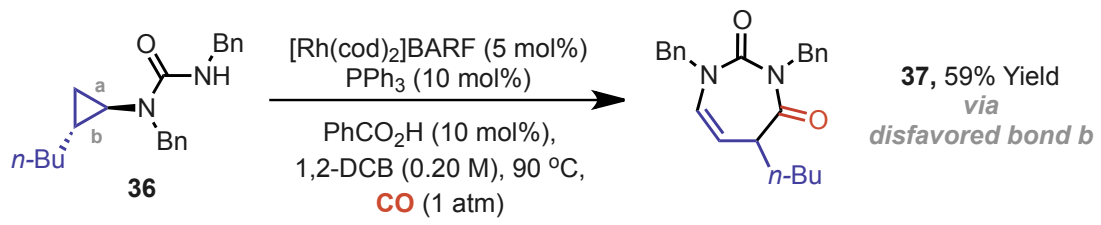

(C) Mechanistic rationale for the observed regioselectivity of $\mathrm{C}-\mathrm{C}$ bond activation
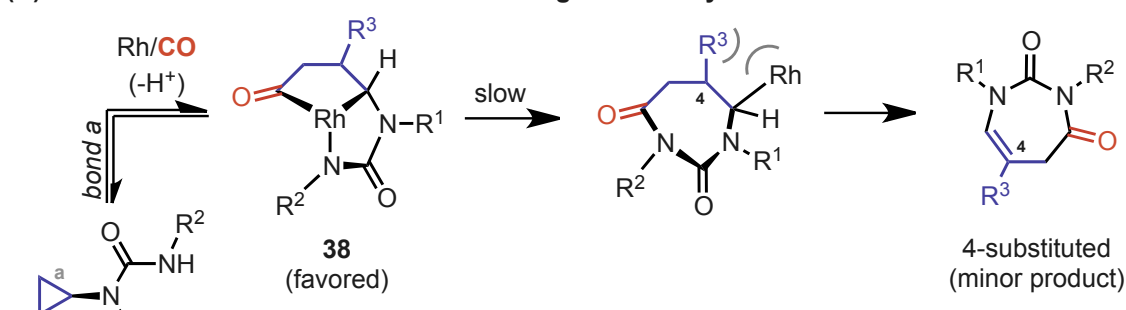

4-substituted<smiles>[R]N[C@@H]1C[C@H]1C</smiles>

$\mathrm{R}^{\mathrm{3}}$

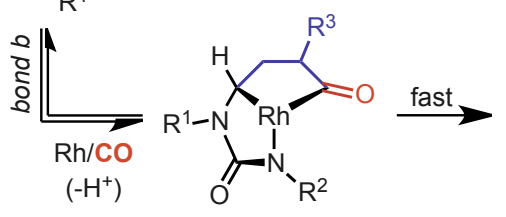

39

(disfavored)

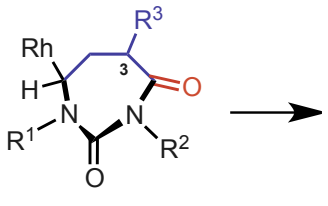

40

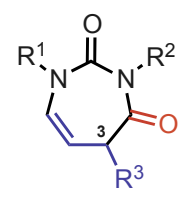

3-substituted (major product)
Scheme 6. 1,3-Diazepanes by C-N reductive elimination from rhodacyclopentanones.

(A) Sequential C-C and C-H activation of aminocyclopropanes to afford azepine structures

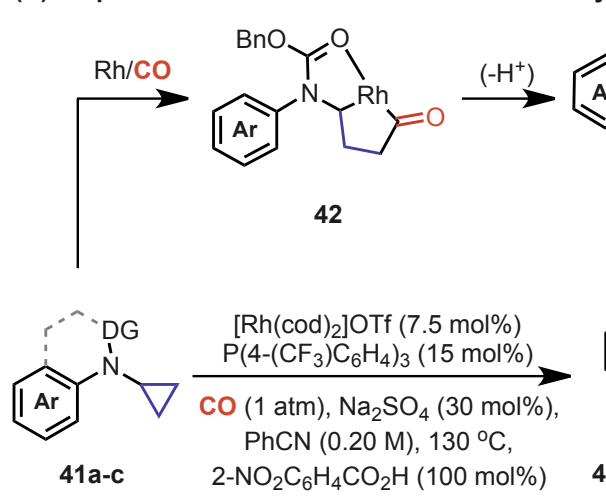<smiles>O=C1CCC(N(C(=O)OCc2ccccc2)c2ccccc2)P1</smiles>

43<smiles>O=C1CCCN(C(=O)OCc2ccccc2)c2ccccc21</smiles><smiles>O=C1CCCN(C(=O)OCc2ccccc2)c2ccc(F)cc21</smiles>

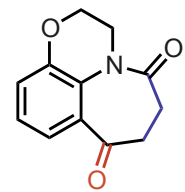

44a, $82 \%$ Yield

44b, $76 \%$ Yield
(B) Processes employing $\mathrm{N}$-vinyl carbamates

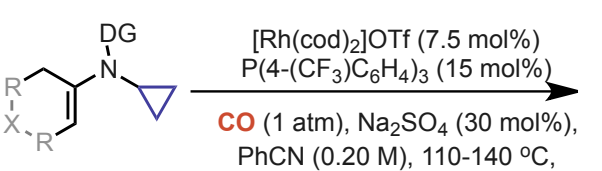$$
\text { acid }(50 \mathrm{~mol} \%)
$$<smiles>O=C1CCCN(C(=O)OCc2ccccc2)C2=C1CCCC2</smiles>

$61 \%$ Yield (no acid)<smiles>O=C1CCCN(C(=O)OCc2ccccc2)C2=C1COCC2</smiles>

$42 \%$ Yield (no acid)<smiles>CCC1=C(C)C(=O)CCCN1C(=O)OCc1ccccc1</smiles>

$41 \%$ Yield (3- $\left.\mathrm{CNC}_{6} \mathrm{H}_{4} \mathrm{CO}_{2} \mathrm{H}\right)$

Scheme 7. Azepines by directed C-C bond activation of aminocyclopropanes.

After extensive investigation, we established that $\mathrm{N}-\mathrm{Cbz}$ and $\mathrm{N}-\mathrm{Ts}$ directing groups are efficient, with the resulting cycloaddition protocol providing access to a range of stereochemically complex perhydroisoindole scaffolds (Scheme 9). Optimized reaction conditions employ a neutral $\mathrm{Rh}(\mathrm{I})$ precatalyst modified by weak donor ligands $\left(\mathrm{AsPh}_{3}\right.$ or 1,4-oxathiane). The protocol is diastereoselective with respect to the stereochemistry of the ring junction (trans favored in all cases), diastereospecific with respect to alkene geometry (e.g. 47a to $48 \mathbf{a} v s$. $47 \mathrm{~b}$ to $48 \mathrm{~b}$ ), and diastereoselective with respect to the $\mathrm{R}^{1}$ and $\mathrm{R}^{2}$-substituents (Scheme 9A). The latter feature provides tentative evidence that rhodacyclopentanone formation is reversible ( $c f$. Scheme 3). As in earlier work, cis- and trans-disubstituted cyclopropanes provided regiodivergent reaction outcomes (Scheme 9B). Subjection of trans-49 to the catalytic protocol revealed preferential activation of the less hindered $\mathrm{C}-\mathrm{C}$ bond a to afford adduct $\mathbf{5 0}$ in good yield and with complete transfer of cyclopropane stereochemistry, which accounts for the high levels of diastereocontrol and regiocontrol observed. Cis-49 underwent activation at the more hindered proximal $\mathrm{C}-\mathrm{C}$ bond $\mathbf{b}$ to provide regioisomeric adduct $\mathbf{5 1}$ with good regiocontrol.

The successful extension of our strategy to processes involving electron neutral cyclopropanes (Scheme 9) suggests that $\mathrm{C}-\mathrm{C}$ bond activation-based multicomponent cycloadditions involving other classes of minimally activated cyclopropanes might be feasible. For example, processes involving cyclopropyl amides would be particularly attractive because the substrates can be accessed directly from cyclopropyl carboxylates. This objective is challenging because $\mathrm{C}-\mathrm{C}$ bond activation-based cycloadditions of electron deficient cyclopropanes are rare. ${ }^{[24]}$ Indeed, to the best of our knowledge, multicomponent carbonylative cycloadditions of non-activated electron-poor cyclopropanes have not been described.

\section{Conclusion}

In summary, protecting group directed carbonylative $\mathrm{C}-\mathrm{C}$ bond activation of cyclopropanes offers a broad platform for the by-product free construction of challenging and stereochemically complex $\mathrm{N}$-heterocyclic ring systems. The strategy exploits the strain embedded within readily available and stereodefined cyclopropanes for reaction initiation, and the resulting metallacycles can be diverted to a range of ' $\mathrm{sp}^{3}$-rich' heterocycles. Further evolution of the approach will include (a) catalyst systems that can activate a wider range of cyclopropanes and (b) processes 


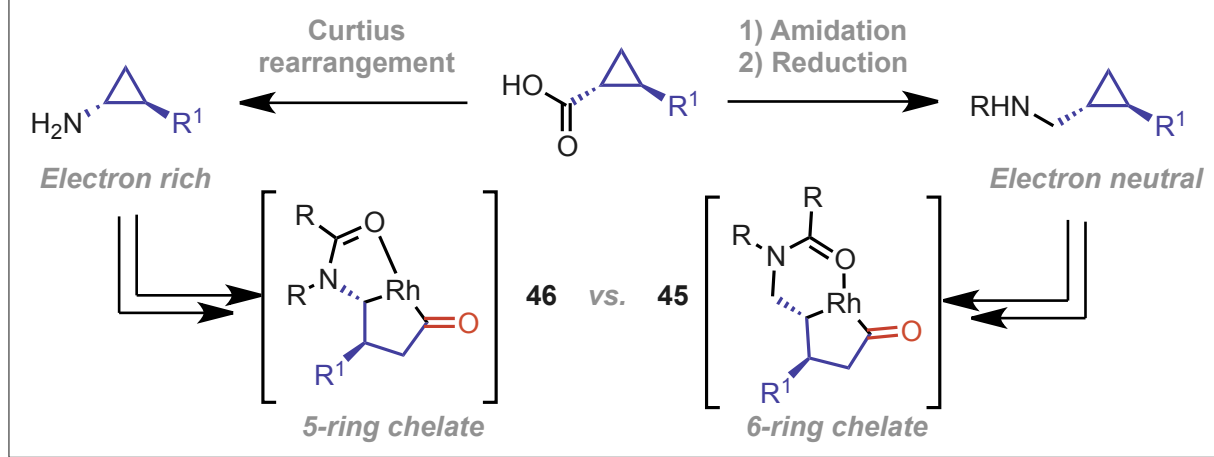

Scheme 8. Directed C-C bond activation of more challenging classes of cyclopropane.

(A) $(3+1+2)$ cycloadditions of electron neutral cyclopropanes, $\mathrm{CO}$ and tethered alkenes

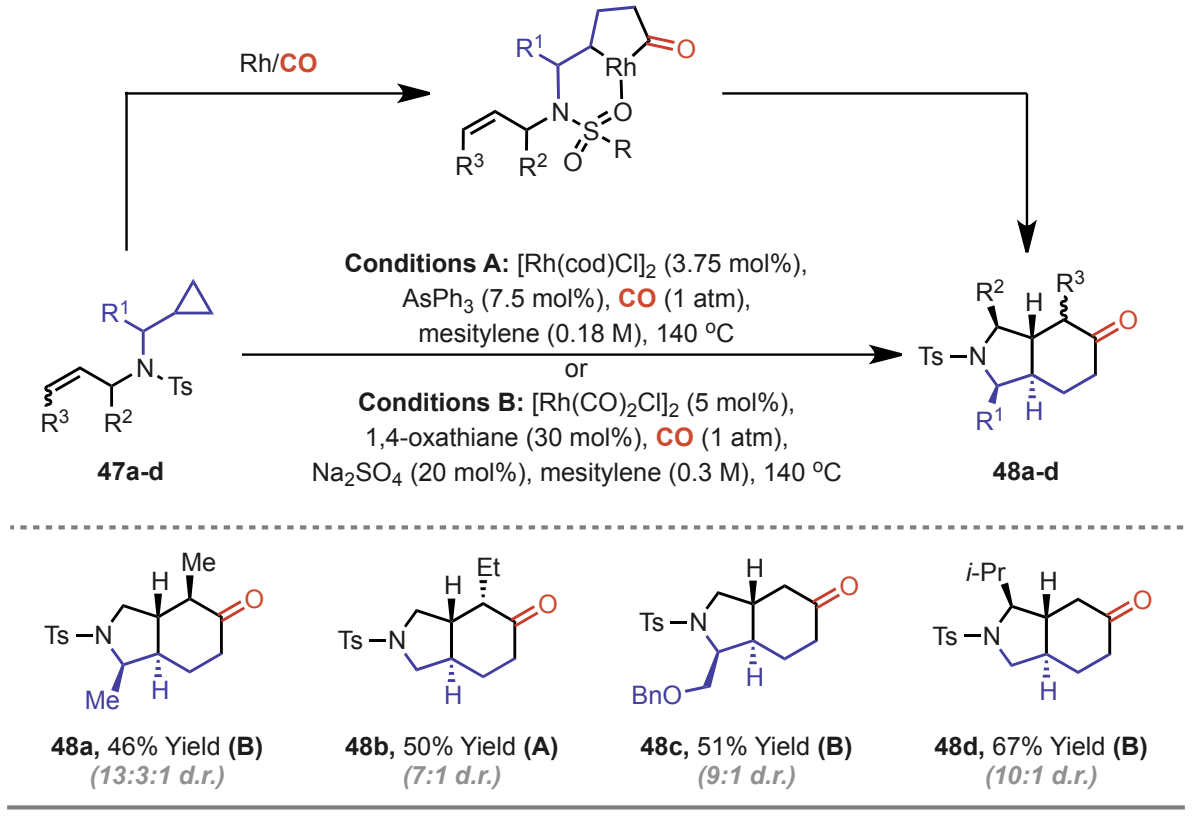

(B) Regioselective C-C bond activation of 1,2-disubstituted cyclopropanes

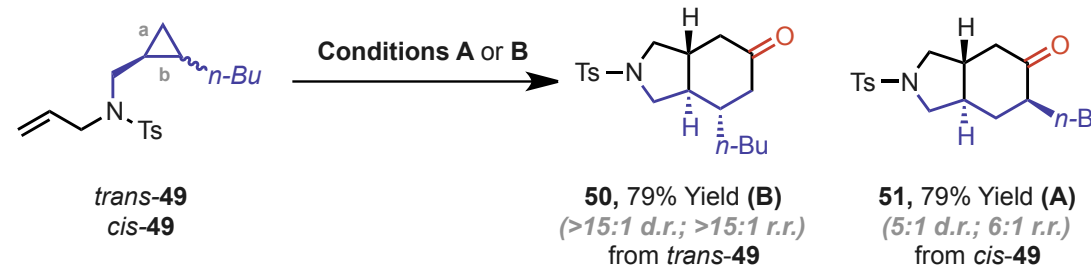

Scheme 9. $(3+1+2)$ cycloadditions of electron neutral cyclopropanes, $\mathrm{CO}$ and tethered alkenes.

that enhance the downstream utility of the key metallacyclic intermediates. Studies towards these broad objectives are ongoing in our laboratory.

\section{Acknowledgements}

We thank the European Research Council (ERC Grant 639594 CatHet) for financial support. J.F.B. is indebted to the Royal Society for a University Research Fellowship.

Received: May 31, 2018

[1] a) F. Lovering, J. Bikker, C. Humblet, J. Med Chem. 2009, 52, 6752; b) W. P. Walters, J. Green, J. R. Weiss, M. A. Murcko, J. Med. Chem. 2011, 54, 6405; c) A. Nadin, C. Hattotuwagama, I. Churcher, Angew. Chem. Int. Ed. 2012, 51, 1114.
[2] For a review on metal insertion into strained heterocycles: C.-Y. Huang, A. G. Doyle, Chem. Rev. 2014, 114, 8153.

[3] Leading references on vinyl cyclopropane-based methodologies: a) P. A. Wender, G. G. Gamber, R. D. Hubbard, L. Zhang, J. Am. Chem. Soc. 2002, 124, 2876; b) H. A. Wegner, A. de Meijere, P. A. Wender, J. Am. Chem. Soc. 2005, 127, 6530; c) Y. Wang, J. Wang, J. Su, F. Huang, L. Jiao, Y. Liang, D. Yang, S. Zhang, P. A. Wender, Z.-X. Yu, J. Am. Chem. Soc. 2007, 129, 10060; d) Y. Feng, Z.-X. Yu, J. Org. Chem. 2015, 80, 1952; (e) L. Jiao, M Lin, L.G. Zhuo, Z.-X. Yu, Org. Lett. 2010, 12, 2528.

[4] Leading references on alkylidenecyclopropane-based methodologies: a) P. A. Inglesby, J. Bacsa, D. E. Negru, P. A. Evans, Angew. Chem. Int. Ed. 2014, 53, 3952; b) S. Mazumder, D. Shang, D. E. Negru, M.-H. Baik, P. A. Evans, J. Am. Chem. Soc. 2012, 134, 20569; c) A. Brandi,
S. Cicchi, F. M. Cordero, A. Goti, Chem. Rev. 2014, 114, 7317.

[5] Leading references on cyclopropene-based methodologies: a) C. Li, H. Zhang, J. Feng, Y. Zhang, J. Wang, Org. Lett. 2010, 12, 3082; b) M. Rubin, M. Rubina, V. Gevorgyan, Chem. Rev. 2007, 107, 3117.

[6] a) G. Fumagalli, S. Stanton, J. F. Bower, Chem. Rev. 2017, 117, 9404; b) L. Souillart, N. Cramer, Chem. Rev. 2015, 115, 9410; For an example of relevance to the work described herein, see: c) Y. Koga, K. Narasaka, Chem. Lett. 1999, $28,705$.

[7] C. F. H. Tipper, J. Chem. Soc. 1955, 2043.

[8] M. H. Shaw, J. F. Bower, Chem. Commun. 2016 , 52,10817

[9] Selected asymmetric approaches to cyclopropane carboxylic acids and derivatives: a) $\mathrm{S}$. Miyamura, M. Araki, T. Suzuki, J. Yamaguchi, K. Itami, Angew. Chem. Int. Ed. 2015, 54, 846; b) L. Gao, G.-S. Hwang, D. H. Ryu, J. Am. Chem. Soc. 2011, 133, 20708; c) Y. Lou, T. P. Remarchuk, E. J. Corey, J. Am. Chem. Soc. 2005, 127, 14223; d) M. M. C. Lo, G. C. Fu, J. Am. Chem. Soc. 1998, 120, 10270.

[10] a) H. Niwa, Y. Uosaki, K. Yamada, Tetrahedron Lett. 1983, 24, 5731; b) K. M. Meragelman, T. C. McKee, J. B. McMahon, J. Nat. Prod. 2004 67,1165 ; c) K. Speck, T. Magauer, Beilstein J. Org. Chem. 2013, 9, 2048; d) J. W. H. Watthey, J. L. Stanton, M. Desai, J. E. Babiarz, B. M. Finn, J. Med. Chem. 1985, 28, 1511.

[11] a) M. H. Shaw, E. Y. Melikhova, D. P. Kloer, W. G. Whittingham, J. F. Bower, J. Am. Chem. Soc. 2013, 135, 4992; For phosphinite directed C-C activation of cyclopropanes, see: b) S. C. Bart, P. J. Chirik, J. Am. Chem. Soc. 2003, 125, 886.

[12] a) F. J. McQuillin, K. C. Powell, J. Chem. Soc. Dalton Trans. 1972, 2129; b) K. G. Powell, F. J. McQuillin, J. Chem. Soc. D 1971, 931; c) D. M. Roundhill, D. N. Lawson, G. Wilkinson, $J$. Chem. Soc. A 1968, 845.

[13] M. H. Shaw, W. G. Whittingham, J. F. Bower, Tetrahedron 2016, 72, 2731.

[14] M. H. Shaw, N. G. McCreanor, W. G. Whittingham, J. F. Bower, J. Am. Chem. Soc. 2015, 137, 463 .

[15] The reverse process has been observed for processes involving insertion of $\mathrm{Rh}(\mathrm{I})$-systems into the acyl-carbon bond of cyclobutanones: a) M. Murakami, H. Amii, K. Shigeto, Y. Ito, J. Am. Chem. Soc. 1996, 118, 8285; b) M. Murakami, H. Amii, Y. Ito, Nature 1994, 370, 540.

[16] C.-Y. Huang, A. G. Doyle, J. Am. Chem. Soc. 2012, 134, 9541 .

[17] M. H. Shaw, R. A. Croft, W. G. Whittingham, J. F. Bower, J. Am. Chem. Soc. 2015, 137, 8054.

[18] An analogy with the stabilities of cis/trans-olefin complexes of rhodium can be made: $\mathrm{R}$. Cramer, J. Am. Chem. Soc. 1967, 89, 4621.

[19] For a recent review, see: J. D. Ricker, L. M. Geary, Top. Catal. 2017, 60, 609.

[20] N. G. McCreanor, S. Stanton, J. F. Bower, J. Am. Chem. Soc. 2016, 138, 11465.

[21] G.-W. Wang, J. F. Bower, J. Am. Chem. Soc. 2018, 140, 2743

[22] E. Vitaku, D. T. Smith, J. T. Njardarson, J. Med. Chem. 2014, 57, 10257.

[23] G.-W. Wang, N. G. McCreanor, M. H. Shaw, W. G. Whittingham, J. F. Bower, J. Am. Chem. Soc. 2016, 138, 13501.

[24] Two-component C-C activation-based cycloadditions of electron-poor 'non-activated' cyclopropanes: a) Q.-S. Liu, D.-Y. Wang, Z.-J. Yang, Y.-X. Luan, J.-F. Yang, J.-F. Li, Y.-G. Pu, M. Ye, J. Am. Chem. Soc. 2017, 139, 18150; b) T. Tamaki, M. Ohashi, S. Ogoshi, Angew. Chem. Int. Ed. 2011, 50, 12067; c) L. Liu, J. Montgomery, Org. Lett. 2007, 9, 3885; d) S. Ogoshi, M. Nagata, H. Kurosawa, J. Am. Chem. Soc. 2006, 128, 5350; e) L. Liu, J. Montgomery, J. Am. Chem. Soc. 2006, 128, 5348. 